\title{
Editors' Reflections on the Tenth Anniversary of LATISS
}

Welcome to the tenth anniversary issue of Learning and Teaching: The International Journal of Higher Education in the Social Sciences (LATISS). This anniversary presents an opportunity for celebration and for reflection on the progress made by the journal. Our aim for the journal, as set out on the website, has remained unchanged:

Learning and Teaching (LATISS) is a peer-reviewed journal that uses the social sciences to reflect critically on learning and teaching in the changing context of higher education. The journal invites students and staff to explore their education practices in the light of changes in their institutions, national higher education policies, the strategies of international agencies and developments associated with the so-called international knowledge economy.

Why did we choose this focus for the journal, and why is it still relevant? The journal was started when the editors were involved in founding the U.K.'s Centre for Learning and Teaching in Sociology, Anthropology and Politics (C-SAP) from 2000 to 2003. This was one of 24 'subject centres', set up by the Higher Education Funding Councils (HEFCs), with the aim of engaging academics and students in developing learning and teaching in their own disciplines. This initiative grew out of the Department of Employment's earlier strategy to fund disciplinary national networks. Sue Wright had set up and run the National Network for Teaching and Learning in Anthropology (NNTLA, 1994-1999) for academics and students to share their knowledge, critical analysis and practice of higher education. The Network also developed a methodology for funding and supporting learning and teaching projects that drew on the concepts, theories and methods of the discipline and was adapted and expanded in C-SAP. Penny Welch had been active in the teaching and learning network of the British Political Studies Association for several years and C-SAP drew in others from politics, international relations, sociology and cultural studies, many of whom are still serving on LATISS' editorial board. 
This focus on disciplines was quite a radical move, as at this time a new profession of generic 'education developers' was gaining strength. They were especially responsible for university-wide courses on teaching and learning for new academics as government policies were putting higher education under great pressure to find new ways of teaching a massive expansion of student numbers within existing staffing levels, and of teaching students the skills deemed necessary to produce 'enterprising' individuals for the labour market (Welch 2009; Wright 2004). Our disciplines could offer a critical perspective on these changes. For example, enterprising employees were expected to be 'reflexive' - a key concept in anthropology. In policyspeak it meant analysing the company's needs, accepting them passively and adjusting oneself to them; whereas in anthropology, reflexive analysis of one's interactions with others was used to understand a social context and work out how to be proactive within it (Wright 2008). These two meanings of being 'reflexive' envisaged two quite different kinds of persons. Similarly, the word 'quality' was important in policy (Jary 2002). It was not a word academics used previously, but they tended to adopt it, as who can be opposed to quality? Yet policy documents and the procedures of the Quality Assurance Agency defined what counted as quality, and measured academic performance accordingly. These new systems of audit (especially in England) put increasingly exhausted academics under pressure to focus just on 'what counts' and thereby adopt the policymakers' and university leaders' redefinition of academic values (Shore and Wright 2000).

In this context, C-SAP funded about sixty projects per year where academics and students used the methods and theories of their own disciplines to analyse the institutional and policy context in which they were operating, to reflect on what they wanted to achieve for themselves and their discipline and to develop courses and educational practices accordingly. One of the funding conditions was that projects should result in a publication, through which colleagues could learn and borrow ideas to develop their own practice. So we established LATISS with the aim of publishing careful analysis of teaching and learning contextualised within changes in institutional, national and international policies.

This remit asked contributors to use their skills as researchers to write about education in a way that connects the detail of practice to analysis of its wider context. Academics had rarely used the disciplinary attributes of their research to analyse their teaching and there was no established genre for writing such articles. The wider literature analysing the higher 
education sector is also quite separate from the literature on curriculum and pedagogy. The editors encouraged $\mathrm{PhD}$ students, postdocs and newly appointed lecturers to write for the journal and they often had little experience (or even training) in writing such articles. In establishing and building up this journal over ten years, the editors have therefore taken on a 'pedagogic' role, working closely with authors where there is clearly a nugget of an excellent paper to develop the analysis and tighten the argument. We make sure to publish at least one general issue per year, with articles about creative ways of teaching 'standard' topics in the social sciences, as well as experimental new topics. As editors, we want to be sure that there is enough information about the author's teaching experiment (what, where, why, how, with what results) or the details of how an organisation worked or about the policy setting, so that readers can reflect on how they can 'borrow' good ideas and to use in their own context.

Although LATISS started in the U.K., we quickly found it chimed with developments in the U.S.A., especially the Carnegie Foundation's work on creating 'communities of practice' to discuss teaching and learning within institutions (Willett 2013) and on helping new academics to develop critically reflexive portfolios of learning and teaching for gaining tenure. In Europe, the Erasmus exchange programme and European-wide disciplinary associations that set up sections on teaching and learning revealed considerable differences in teaching and learning within the same discipline (Drackle and Edgar 2004). LATISS has become an outlet for material generated by the European Teaching Anthropology Network (Krause Jensen and Garsten 2014) and has published several special issues arising from sessions at conferences of national disciplinary associations, not least in the U.S.A. (Feldman and Henry 2009; Hunter and Abelmann 2013; Posecznick and Shumar 2014; Shear and Hyatt 2010; Urciuoli 2013). As the titles of these special issues suggest, the journal has addressed questions of how to educate students to be critical and reflexive in conditions of neo-liberalism, explored engaged scholarship, service learning and citizenship education (Bernstein 2009) as well as critically examining the impacts on 'excellence' and 'equality' of management technologies and governance (for example, Morrish and Sauntson 2010; Vonderau 2015). PhD students have been active internationally in analysing changes in the practice and context of their work (for example, Nielsen and Thorkelsen 2012; Morrison et al. 2011). More recently, there is an increasing interest in learning and teaching in West and East Asia, notably China (Bregnbaek 2011; Hansen and Thørgersen 2015) 
and in transnational or 'global' education (Nielsen 2012; Trahar 2015). We started this anniversary year by considering not only how to shape teaching and learning by engaging critically with neo-liberal contexts but how to recreate universities for the public good (Greenwood and Wright 2017). With Berghahn, we have also launched a book series, 'Critical Perspectives in Higher Education', which includes both entirely new material and collections of LATISS articles on particular themes.

If the remit for the journal, quoted above, started from a U.K. context ten years ago, it now has even more resonance as academics and students reflect on the values and practices of higher education in the social sciences in their own classroom and institutional settings, and as they come increasingly under the influence of national and regional policies, and imperatives to engage in international activities and 'be global'. A critical space for examining what academics and students are trying to achieve through their higher education practices, and how to sustain these values and ambitions in the face of new administrative and learning technologies, shifts in the management and governance of higher education, and national and regional ambitions for universities to drive a knowledge economy seems more important now than ever.

\section{Susan Wright and Penny Welch}

\section{References}

Bernstein, J. (ed.) (2009) Perspectives on Citizenship Education, LATISS 2, no. 3.

Bregnbaek, S. (2011) 'A public secret: "Education for quality" and suicide among Chinese elite university students', LATISS 4, no. 3: 19-37.

Drackle, D. and Edgar, I. (eds) (2004) Current Policies and Practices in European Social Anthropology Education, Oxford: Berghahn.

Feldman, K. and Henry, L. (eds) (2009) Transforming Graduate Education in Applied Anthropology in the U.S., LATISS 2, no. 2.

Greenwood, D. and Wright, S. (eds) (2017) Recreating Universities for the Public Good, LATISS 10, no. 1.

Hansen, A. S. and Thørgersen, S. (eds) (2015) Coping with Cultural Difference: Chinese Students and the Internationalisation of Higher Education, LATISS 8, no. 3.

Hunter, G. and Abelmann, N. (eds) (2013) Ethnographies of the University, LATISS 6, no. 3.

Jary, D. (ed.) (2002) Benchmarking and Quality Management, Birmingham: C-SAP publications. 
Krause Jensen, J. and Garsten, C. (eds) (2014) Neoliberal Turns in Higher Education, LATISS 7, no. 3.

Morrish, L. and H. Sauntson, H. (eds) (2010) Gender and Sexuality: The Discursive Limits of 'Equality' in Higher Education, LATISS 3, no. 2.

Morrison, E., Rudd, E. and Nerad, M. (2011) 'Early careers of recent U.S. social science PhDs', LATISS 4, no. 2: 6-29.

Nielsen, G.B. (ed.) (2012) Higher Education Gone Global, LATISS 5, no. 3.

Nielsen, K. and Thorkelsen, E. (eds) (2012) Towards an Anthropology of Anthropology: The Socialisation of Aspiring Anthropologists, LATISS 5, no. 1.

Posecznick, A. and Shumar, W. (eds) (2014) Collusion, Complicity and Resistance: Theorising Academics, the University and the Neoliberal Market Place, LATISS 7, no. 1.

Shear, B. and Hyatt, S.B. (2010) Learning under Neoliberalism: Ethnographies of Governance in Higher Education, LATISS 3, no. 3.

Shore, C. and Wright, S. (2000) 'Coercive accountability: The rise of audit culture in higher education', in M. Strathern (ed.) Audit Cultures: Anthropological Studies in Accountability, Ethics and the Academy, London: Routledge, 57-89.

Trahar, S. (ed.) (2015) Learning and Teaching in Transnational Higher Education, LATISS 8, no. 1 .

Urciuoli, B. (ed.) (2013) The Promise and Practice of Service Learning and Engaged Scholarship, LATISS 6, no. 2.

Vonderau, A. (2015) 'Audit culture and the infrastructures of excellence: On the effects of campus management technologies', LATISS 8, no. 2: 29-47.

Welch, P. (2009) 'The evolution of government policy towards English higher education 1979-2007', LATISS 2, no. 2: 96-122.

Willett, G. (2013) 'Beyond pedagogy: Community feeling, educational development and power in a U.S. liberal arts college', LATISS 6, no. 1: 47-71.

Wright, S. (2004) 'Markets, corporations, consumers? New landscapes in higher education', LATISS 1, no. 2: 71-93.

Wright, S. (2008) 'Governance as a Regime of Discipline', in N. Dyck (ed.) Exploring Regimes of Discipline: The Dynamics of Restraint, Oxford: Berghahn, 75-98. 